\title{
An inverse association between West Nile virus serostatus and avian malaria infection status
}

\author{
Matthew Cl Medeiros ${ }^{1 *}$, Tavis K Anderson ${ }^{2}$, Jenni M Higashiguchi ${ }^{1 \wedge}$, Uriel D Kitron ${ }^{3}$, Edward D Walker ${ }^{4}$, \\ Jeffrey D Brawn ${ }^{5}$, Bethany L Krebs ${ }^{5}$, Marilyn O Ruiz ${ }^{6}$, Tony L Goldberg ${ }^{7}$, Robert E Ricklefs ${ }^{1}$ and Gabriel L Hamer ${ }^{4,8}$
}

\begin{abstract}
Background: Various ecological and physiological mechanisms might influence the probability that two or more pathogens may simultaneously or sequentially infect a host individual. Concurrent infections can have important consequences for host condition and fitness, including elevated mortality risks. In addition, interactions between coinfecting pathogens may have important implications for transmission dynamics.

Methods: Here, we explore patterns of association between two common avian pathogens (West Nile virus and avian malaria parasites) among a suburban bird community in Chicago, IL, USA that share mosquito vectors. We surveyed 1714 individual birds across 13 species for both pathogens through established molecular protocols.

Results: Field investigations of haemosporidian and West Nile virus (WNV) infections among sampled birds yielded an inverse association between WNV serostatus and Plasmodium infection status. This relationship occurred in adult birds but not in juveniles. There was no evidence for a relationship between Haemoproteus infection and WNV serostatus. We detected similar prevalence of Plasmodium among birds captured with active WNV infections and spatiotemporally paired WNV-naïve individuals of the same species, demonstrating that the two pathogens can co-infect hosts.

Conclusions: Mechanisms explaining the negative association between WNV serostatus and Plasmodium infection status remain unclear and must be resolved through experimental infection procedures. However, our results highlight potential interactions between two common avian pathogens that may influence their transmission among hosts. This is especially relevant considering that West Nile virus is a common zoonotic pathogen with public health implications. Moreover, both pathogens are instructive models in infectious disease ecology, and infection with either has fitness consequences for their avian hosts.
\end{abstract}

Keywords: Parasite-parasite interactions, Coinfection, Concurrent infection, Concomitant infection, West Nile virus, Haemosporida, Avian malaria

\section{Background}

Numerous pathogens co-circulate within host populations, and various mechanisms influence the probability that these pathogens may cause concurrent or consecutive infections within a host individual [1-4]. For instance, pathogens with similar ecological tolerances and vectors might be more likely to co-occur within a host [5], while differences may result in non-overlapping distributions across hosts over space and time. Infection can influence

\footnotetext{
* Correspondence: mcmn92@umsl.edu

Deceased

'Department of Biology, University of Missouri-St. Louis, One University

Boulevard, St. Louis, MO 63121, USA

Full list of author information is available at the end of the article
}

the susceptibility of a host to another pathogen [2,4], and this interaction can alter pathogen transmission dynamics at the population level [1]. Negative associations between pathogens occur when an established pathogen lowers the infection success of another pathogen through immunemediated mechanisms [3,4], resource competition, or host mortality [4]. Conversely, established parasites can increase the probability of infection of another pathogen through facilitation [1,2]. Concurrent infections can elevate host morbidity and mortality rates [6], although this effect often depends on the particular pathogens involved $[7,8]$. Thus, pathogen-pathogen interactions can greatly influence the course of infection within the host and the 
distribution of pathogens among host individuals at the population level.

Avian Haemosporida are an instructive model system for disease ecology, including the consequences of concurrent infections. Mixed avian haemosporidian infections can be common within individuals in some host populations [9]. Both field- and laboratory-based studies have demonstrated that co-infection with different haemosporidian parasites can depress host fitness more than single infections $[10,11]$. However, few studies have explored the interactions of avian Haemosporida with other pathogens (in contrast to mammalian malaria $[7,12]$, however, see Atkinson et al. [5], Barnett [13]). This absence of knowledge is particularly concerning because birds are primary reservoirs for many zoonotic pathogens, including arthropod-borne encephalitis viruses whose course of infection may be influenced by concurrent protozoan infections [12]. Thus, understanding interactions between Haemosporida and other pathogens could have important implications for disease surveillance and animal and human health.

Here, we explore patterns of association between avian Haemosporida and West Nile virus (WNV), an important zoonotic pathogen. We consider the genera Plasmodium and Haemoproteus, which are diverse and abundant Haemosporida that infect a range of avian host species [14]. The two genera differ in their lifecycles and transmission dynamics $[14,15]$. Most notably, Plasmodium replicates asexually within erythrocytes leading to the rupture of blood cells, and is vectored by mosquitoes (Culicidae). In Haemoproteus infections, asexual reproduction is limited to the viscera and vascular endothelium, and the parasites are vectored by Culicoides biting midges (Ceratopogonidae). Haemosporida parasites of both genera are often pathogenic [16-18], but virulence varies with pathogen lineage and host species $[18,19]$. Infections can maintain throughout the life of the host, but may disappear from the bloodstream and relapse later [14]. Vernal recrudescence, a phenomenon in which dormant infections acquired during previous transmission seasons relapse into the bloodstream in the spring, is common in temperate latitudes [14]. WNV was introduced to North America in 1999 and spread across most of the continent within 5 years [20,21]. In 2012, one of the largest WNV epidemics to date occurred in North America (CDC). WNV is maintained in a transmission cycle generally between mosquitoes and birds, but is occasionally transmitted to other hosts, including humans [21]. Symptoms of WNV infection in humans may be mild to severe, occasionally including neurologic impairment or death [22]. WNV infection also has severe fitness consequences for some avian host species [23], and its introduction coincided with population declines in some North American bird species [24]. Associations between WNV and trypanosomes [25] and
Culex flavivirus [26] have previously been documented in mosquitoes. However, interactions of WNV with Haemosporida within birds have received comparatively little attention.

The similar ecology of avian Haemosporida and WNV suggests that interactions between these pathogens might occur in North America. Both WNV and avian Haemosporida are common in American robins (Turdus migratorius), northern cardinals (Cardinalis cardinalis), and house sparrows (Passer domesticus) [27]. Individuals of these species also host WNV $[28,29]$ and appear to be the vertebrate drivers of local WNV transmission dynamics in the eastern Unites States [30,31]. In addition, WNV and avian Plasmodium share the same vectors (Culex pipiens and $C x$. restuans) in eastern North America [14,27,32-34], suggesting similar host encounter rates between the pathogens. In this study, we explore the potential interaction between WNV and Haemosporida near Chicago, IL, USA, and show that WNV seropositive birds have a lower probability of haemosporidian infection.

\section{Methods}

\section{Sampling and pathogen testing}

The study was conducted at 17 sites in suburban Chicago, IL, USA [35]. Birds were captured in mist-nets from May-October during 2006-2007 and screened for avian Haemosporida [27]. A blood sample was taken from the jugular vein and centrifuged to separate serum from blood cells. Packed blood cells were preserved in Longmire's lysis buffer. Samples were digested with Proteinase K overnight at $60^{\circ} \mathrm{C}$. DNA was extracted via protein precipitation with $5 \mathrm{M}$ ammonium acetate, and purified with a standard alcohol precipitation. DNA samples were screened for haemosporidian parasites by polymerase chain reaction (PCR) targeting a segment of the mitochondrial 16S rRNA gene [36]. Samples that tested positive by this method were then subjected to a nested PCR that targeted a 552base pair fragment of the haemosporidian cytochrome $b$ gene $[37,38]$. We generally obtained sequences from $\sim 85 \%$ of samples that screened positive for a haemosporidian infection with the 16S rRNA primers.

Avian haemosporidian taxonomy is unresolved at the species level, and currently relies on cytochrome $b$ sequences to identify parasite taxa [39-41]. We therefore separated evolutionary lineages of Plasmodium and Haemoproteus following Ricklefs et al. [37]. Generally, haemosporidian taxa were categorized as sets of closely related ( $<1 \%$ sequence divergence) monophyletic parasite cytochrome $b$ haplotypes recovered from the same set of host species. Two lineages presented here were identical to previously named morphospecies (Plasmodium cathemerium and Plasmodium elongatum, Genbank accession no. AY377128 and AY733088, respectively). 
Avian serum was used to test for the presence of WNV antibodies using inhibition ELISA, and to screen individuals for circulating WNV with a quantitative reverse transcriptase-PCR (methodology for the ELISA and quantitative reverse transcriptase-PCR summarized in Hamer et al. [42]). Among birds screened for malaria, 7\% were seropositive for WNV antibodies. 5728 birds (including birds screened for haemosporian parasites here) were screened for WNV $[35,43]$ across an extended WNV study from 2005-2011 in the study site. Only 27 (0.5\%) individuals were positive for the virus by RT-PCR [43]. To compare concurrent infection rates of WNV and Haemosporida, blood samples from 26 of these birds were screened for haemosporidian infections. In addition, we screened 26 spatiotemporally paired WNV-negative samples of the same species and age. Each WNV positive and negative pair was sampled from the same site, generally on the same day.

\section{Haemosporidian phylogeny}

We aligned cytochrome $b$ sequences (512 bp and subsequently inferred phylogenetic relationships among haemosporidian parasites using maximum-likelihood methods, invoking a general time-reversible (GTR) model of nucleotide substitution with $\Gamma$-distributed rate variation among sites in MEGA5 [44]. Statistical support was estimated for individual nodes by bootstrap analysis (1000 replicates), and the best-scoring tree was mid-point rooted for clarity. The resulting tree (Additional file 1: Figure S1) was used primarily to assign lineages to genera. Sequences of all unique cytochrome $b$ lineages are deposited in GenBank (accession no. KC789821-KC789828, KM280598KM280635.

\section{Statistical analyses}

We used a series of generalized linear mixed models (GLMM) with a binomial error distribution to test for an association between WNV serostatus and Haemosporida infection status for birds sampled between 20062007. All GLMMs were performed in the lme4 package in R. Our data were heterogeneous and unbalanced with respect to other variables that potentially influence haemosporidian infection across WNV-seropositive and naïve individuals. Therefore, we included species as a random factor in all models tested. Moreover, year of sampling (two levels: 2006 and 2007), month of sampling (four levels: May/June, July, August, September/ October), age class at sampling (two levels: hatch-year juvenile $[\mathrm{HY}]$ or after hatch-year adult [AHY]), WNV serostatus (presence or absence of WNV antibodies), and an age* WNV serostatus interaction, were included as covariates in a full model.

We used AICc multimodel inference to select among a set of candidate models (SOM-Section 2) that included all combinations of the five fixed effect variables. We estimated the natural average of the estimate and associated unconditional 95\% confidence intervals [45] with the R package "AICcmodavg". WNV serostatus model estimates $\left(\beta_{W N V}\right)$ represent the change in the log-odds of Haemosporida infection for WNV seropositive relative to WNV seronegative individuals. Within the text, values of $\beta_{W N V}$ are presented as the natural average of the model coefficients \pm 1.96 * unconditional (model-averaged) standard error (SE). When calculating the modelaveraged $\beta_{W N V}$, we excluded models with the age*WNV interaction term. We performed the basic modeling approach detailed above for five separate analyses in which the dependent variable of infection status was defined differently: 1) total Haemosporida; 2) total Plasmodium; 3) total Haemoproteus; 4) Plasmodium cathemerium; and 5) Plasmodium elongatum. We performed the basic modeling approach detailed above for data on 1714 individuals of 13 well-sampled species $(\mathrm{N}>10)$ that had both haemosporidian infections and WNV seropositive individuals. We excluded records of other species that did not fit the criteria above, or those with missing data (ie. unknown age, WNV serological status, etc.). All species along with their sample sizes across age class, Plasmodium prevalence, Haemoproteus prevalence, and WNV seroprevalence are listed in Additional file 1: Table S1.

\section{Ethical approval}

Fieldwork was authorized by the appropriate permits including a Federal Bird Banding Permit no. 06507, animal-use approvals from the University of Illinois Animal Use Protocol no. 03034, and Institutional Animal Care and Use Committee at Michigan State University, Animal Use Form no. 12/03-152-00.

\section{Results}

\section{WNV serostatus and haemosporida infection}

Among the community-level dataset, the prevalence of Plasmodium and Haemoproteus parasites was 0.26 and 0.08 respectively. Seroprevalence of WNV antibodies was 0.07 .

The best-fit model explaining total Haemosporida infection status included month of capture, year of capture, age, WNV serostatus, and age ${ }^{*} \mathrm{WNV}$ serostatus interaction $\left(w_{i}=0.97\right)$, and was differentiated from other models (Table 1). Thus, we split the dataset across age class to investigate the interaction. For adults, WNV serostatus was an important predictor of Haemosporida infection (Table 2). The best-fit model included year and WNV serostatus $\left(w_{i}\right.$ $=0.69$ ) and was differentiated from a model that only included year as a fixed effect $\left(\triangle \mathrm{AICc}=5.5, w_{i}=0.04\right)$. The model-averaged WNV serostatus effect $\left(\beta_{W N V}=-0.78 \pm\right.$ 0.59 ) indicated that the presence of WNV antibodies reduced the odds of a concurrent haemosporidian infection by a factor of 2.2 for adult birds. Among juvenile birds, the 
Table 1 A summary AICc table for generalized linear mixed models that considered both host ages simultaneously and an age*WNV serostatus interaction effect

\begin{tabular}{|c|c|c|c|c|}
\hline & $\mathrm{K}$ & $\mathrm{AICc}$ & $\triangle \mathrm{AICC}$ & $w_{i} \mathrm{AICc}$ \\
\hline \multicolumn{5}{|l|}{ a) Total Haemosporida } \\
\hline mon+yr+age+wnv+wnv $\mathbf{v}^{*}$ age & 9 & 2056.5 & 0.0 & 0.97 \\
\hline mon+yr+age+wnv & 8 & 2064.0 & 7.5 & 0.02 \\
\hline \multicolumn{5}{|l|}{ b) Total Plasmodium } \\
\hline mon+yr+age+wnv+wnv*age & 9 & 1704.7 & 0.0 & 0.99 \\
\hline mon+yr+age+wnv & 8 & 1713.9 & 9.1 & 0.01 \\
\hline \multicolumn{5}{|l|}{ c) Total Haemoproteus } \\
\hline mon & 5 & 742.3 & 0.0 & 0.32 \\
\hline mon+yr & 6 & 744.1 & 1.8 & 0.13 \\
\hline mon+age & 6 & 744.2 & 1.9 & 0.12 \\
\hline mon+wnv & 6 & 744.3 & 2.0 & 0.12 \\
\hline \multicolumn{5}{|l|}{ d) $P$. cathemerium } \\
\hline mon+yr+age+wnv & 8 & 823.4 & 0.0 & 0.59 \\
\hline mon+yr+age+wnv+wnv*age & 9 & 825.2 & 1.8 & 0.24 \\
\hline \multicolumn{5}{|l|}{ e) P. elongatum } \\
\hline yr+age+wnv & 5 & 586.23 & 0.0 & 0.40 \\
\hline yr+age+wnv+wnv*age & 6 & 587.0 & 0.8 & 0.27 \\
\hline yr+age & 4 & 587.6 & 1.4 & 0.20 \\
\hline
\end{tabular}

Models with $\triangle \mathrm{AICc}<3.0$ are shown. However, when only one model had a $\Delta \mathrm{AlCc}<3.0$, the next best model was listed for comparison. Abbreviations are as follows: mon = month of capture, $y r=$ year of capture, age = age class, wnv $=$ WNV serostatus (seropositive, seronegative). Species was a random effect in all models tested.

Table 2 A summary AICc table for generalized linear mixed models performed on adults and juveniles separately

\begin{tabular}{llll}
\hline $\mathrm{K}$ & $\mathrm{AICC}$ & $\triangle \mathrm{AICC}$ & $w_{i} \mathrm{AICC}$
\end{tabular}

a) Total Haemosporida-adults

$\begin{array}{lllll}\text { yr+wnv } & 4 & 1138.9 & 0.0 & 0.69 \\ \text { mon+yr+wnv } & 7 & 1140.9 & 2.1 & 0.24\end{array}$

b) Total Haemosporida-juveniles

$\begin{array}{lllll}\text { mon+yr } & 6 & 862.7 & 0.0 & 0.73 \\ \text { mon+yr+wnv } & 7 & 864.7 & 2.0 & 0.27\end{array}$

c) Total Plasmodium-adults

$\begin{array}{lllll}\text { yr+wnv } & 4 & 871.4 & 0.0 & 0.64 \\ \text { mon+yr+wnv } & 7 & 872.6 & 1.2 & 0.35\end{array}$

d) Total Plasmodium-juveniles

\begin{tabular}{lllll} 
mon+yr & 6 & 785.5 & 0.0 & 0.72 \\
mon+yr+wnv & 7 & 787.4 & 1.9 & 0.28 \\
\hline
\end{tabular}

Only models with $\triangle \mathrm{AICc}<3.0$ are shown. Abbreviations are as follows: mon $=$ month of capture, $\mathrm{yr}=$ year of capture, $\mathrm{wnv}=$ WNV serostatus (seropositive, seronegative). Species was a random effect in all models tested. best-fit model included month and year of capture $\left(w_{i}=\right.$ 0.73), and was differentiated from a model that contained month, year, and WNV serostatus $\left(\triangle \mathrm{AICc}=2.0, w_{i}=0.27\right)$. The confidence limits of the WNV serostatus effect $\left(\beta_{W N V}=-0.06 \pm 0.94\right)$ for juvenile hosts included zero, providing low support for an association between WNV serostatus and Haemosporida infection among hatch-year birds.

The best-fit model explaining total Plasmodium infection status included month of capture, year of capture, age, WNV serostatus, and age ${ }^{*}$ WNV serostatus interaction $\left(w_{i}=0.99\right)$, and was differentiated from other models (Table 1). Splitting the dataset across age classes, the best-fit model for adult birds included year and WNV serostatus ( $w_{i}=0.64$, Table 2$)$, but was indistinguishable from a model that included month, year, and WNV serostatus $\left(\triangle \mathrm{AICc}=1.2, w_{i}=0.35\right)$. The modelaveraged WNV serostatus effect $\left(\beta_{W N V}=-1.34 \pm 0.84\right)$ indicated that the presence of WNV antibodies reduced the odds of a concurrent Plasmodium infection by a factor of 3.8 for adult birds (Figure 1). For juvenile birds, the best-fit model included month and year of capture $\left(w_{i}=0.72\right.$, Table 2$)$, but was indistinguishable from a model that included those fixed effects and WNV serostatus $\left(\triangle \mathrm{AICc}=1.9, w_{i}=0.28\right)$. The confidence limits of the WNV serostatus effect $\left(\beta_{W N V}=-0.18 \pm 0.94\right)$ for juvenile hosts included zero, providing low support for an association between WNV serostatus and Plasmodium infection among hatch-year birds.

Asynchronous infection dynamics between WNV and Plasmodium in the study site could explain the inverse relationship between WNV serostatus and the probability of a Plasmodium infection among adult birds. Generalized linear mixed models with binomial error distributions and species as a random effect revealed that the probability of having WNV antibodies or a Plasmodium infection differed across months. WNV seroprevalence in adult birds increased across the transmission season (likelihood ratio test of nested models, $\left.\chi^{2}=8.6, \mathrm{df}=3, \mathrm{p}<0.05\right)$. WNV seroprevalence was lowest in May-June, moderate in July and August, and highest in September-October. In contrast, the probability of Plasmodium infection was consistent across the season (likelihood ratio test of nested models, $\chi^{2}=2.6, \mathrm{df}=3$, $\mathrm{p}>0.4)$. The different temporal patterns of WNV seropositve and Plasmodium infected hosts across the transmission season did not solely drive the negative association between these variables. WNV serostatus remained an important negative predictor of Plasmodium infection status (Additional file 1: Table S11) among adult hosts sampled during the later portion of the transmission season (July through October) when there was more overlap between Plasmodium-infected and WNV-seropositive individuals. The model-averaged WNV serostatus effect $\left(\beta_{W N V}=-1.71 \pm 1.18\right)$ indicated 


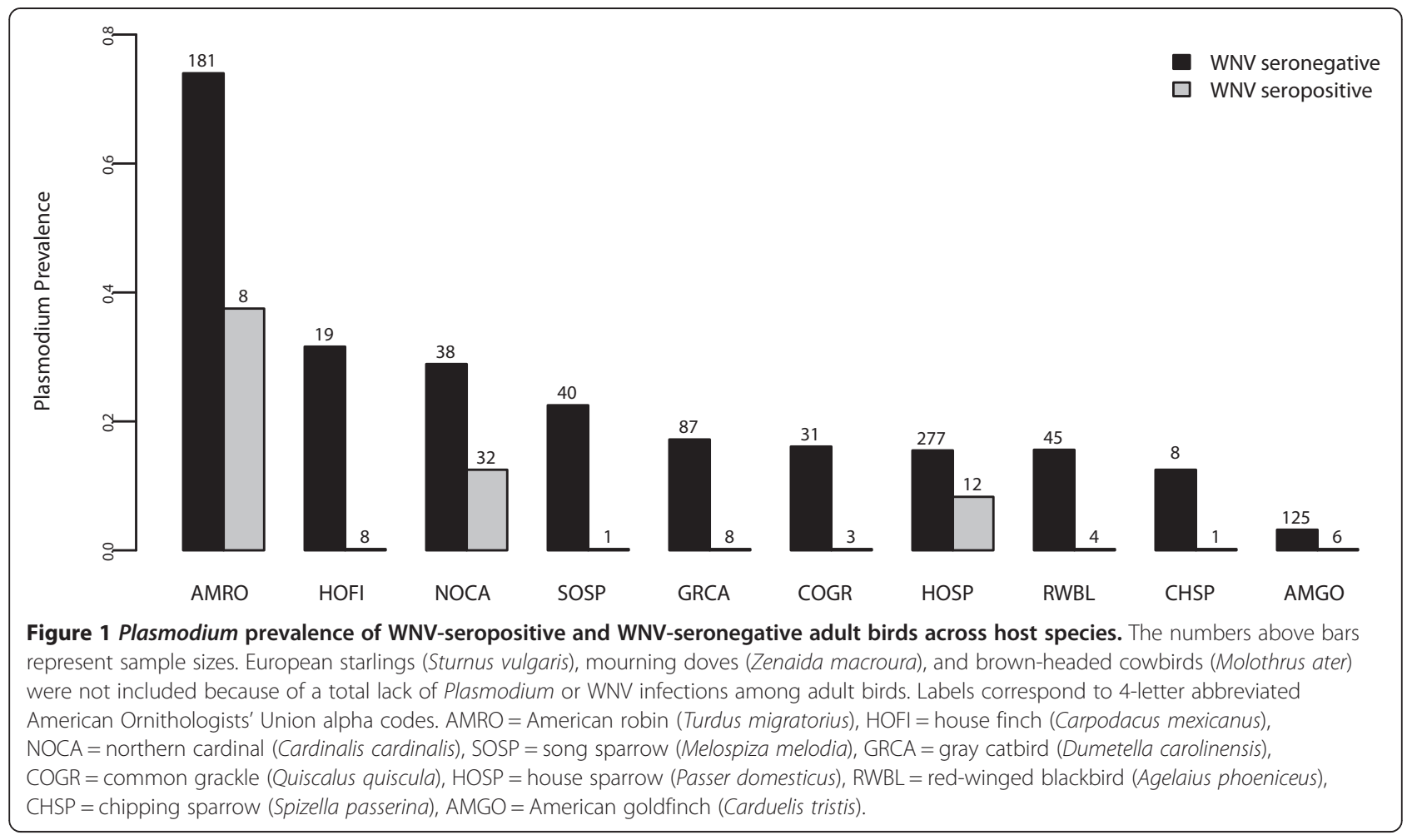

that the presence of WNV antibodies reduced the odds of a Plasmodium infection by a factor of 5.5 for adult birds.

We found no support for an association between WNV serostatus and Haemoproteus infection (Table 1). The best-fit model included month $\left(w_{i}=0.32\right)$, however, three other models had $\triangle \mathrm{AICc}<3$ (Table 1 ). The confidence limits of the WNV serostatus effect on Haemoproteus included zero $\left(\beta_{W N V}=0.08 \pm 0.67\right)$.

Results with two well-sampled Plasmodium lineages were broadly similar to those obtained with total Plasmodium. The best fit model for Plasmodium cathemerium included the fixed effects of month, year, age, and WNV serostatus $\left(w_{i}=0.59\right.$, Table 1$)$, but was indistinguishable from a model that included those fixed effects and the age ${ }^{*} \mathrm{WNV}$ serostatus interaction $(\triangle \mathrm{AICc}=1.8$, $\left.w_{i}=0.24\right)$. However, the best-fit model was differentiated from a model that included only month, year, and age $\left(\triangle \mathrm{AICc}=4.0, w_{i}=0.08\right)$. The model-averaged WNV serostatus effect $\left(\beta_{W N V}=-1.22 \pm 1.10\right)$ indicated that the presence of WNV antibodies reduced the odds of a concurrent $P$. cathemerium infection by a factor of 3.4 for adult birds. The best-fit model for Plasmodium elongatum included the fixed effects of year, age, and WNV serostatus $\left(w_{i}=0.40\right.$, Table 1$)$, but was indistinguishable from a model that included only year and age $(\triangle \mathrm{AICc}=$ $\left.1.4 w_{i}=0.20\right)$. The model-averaged WNV serostatus estimate $\left(\beta_{W N V}=-0.89 \pm 1.0\right)$ indicated that the presence of WNV antibodies reduced the odds of a concurrent $P$. elongatum infection by a factor of 2.4, although the confidence limits of the estimate included zero. Full AICc tables for all analyses are shown in the Additional file 1: Tables S2-11.

\section{Analysis of WNV-positive birds}

Nine birds of 26 that were positive for WNV had Haemosporida infections, eight of which were Plasmodium. A similar number $(8 / 26)$ of spatiotemporally paired individuals of the same species that did not test positive for WNV had haemosporidian infections ( $\mathrm{p}=1.0$, fisher exact test). All of these were Plasmodium infections (Table 3). WNV-infected birds appear to be infected with a diversity of Haemosporida at a comparable rate relative to birds without WNV infections (Table 3).

\section{Discussion}

Haemosporida are common parasites of suburban birds in North America, yet little is known about their potential interactions with WNV. Our data demonstrate a negative association between the presence of WNV antibodies and avian Haemosporida infection among urban birds of Chicago. However, this negative association was context-dependent, varying with respect to haemosporidian taxonomy and host age. The presence of WNV antibodies was associated with a lower probability of infection with avian Plasmodium taxa, but not Haemoproteus. Moreover, the inverse association between WNV serostatus and Plasmodium infection status was present 
Table 3 Number of Haemosporida infections and total host individuals sampled among birds with active WNV infections and spatiotemporally paired individuals of the same age and host species that were naïve to WNV

\begin{tabular}{|c|c|c|c|c|}
\hline \multicolumn{5}{|l|}{ a) West Nile virus positive } \\
\hline & Haemosporida infections & Plasmodium infections & Total sampled & Haemosporidian Lineages \\
\hline American robin $^{1}$ & 2 & 1 & 2 & CHI04PL, CHI02PL, CHI19PA \\
\hline Gray catbird & 1 & 0 & 1 & CHI01PA \\
\hline House finch & 0 & 0 & 3 & \\
\hline House sparrow & 4 & 4 & 15 & P. cathemerium, CHI05PL, P. elongatum \\
\hline House wren & 0 & 0 & 1 & \\
\hline Northern cardinal & 2 & 2 & 2 & P. cathemerium, P. elongatum \\
\hline Red-winged blackbird & 0 & 0 & 1 & \\
\hline Northern flicker & 0 & 0 & 1 & \\
\hline Total & 9 & 7 & 26 & \\
\hline \multicolumn{5}{|c|}{ b) West Nile virus negative } \\
\hline American robin ${ }^{1}$ & 1 & 1 & 2 & CHI04PL ${ }^{1}$, P. elongatum \\
\hline Gray catbird & 0 & 0 & 1 & \\
\hline House finch & 1 & 1 & 3 & P.cathemerium \\
\hline House sparrow $^{2}$ & 4 & 2 & 15 & P.cathemerium, P. elongatum \\
\hline house wren & 0 & 0 & 1 & \\
\hline Northern cardinal & 1 & 1 & 2 & P. elongatum \\
\hline Red-winged blackbird & 1 & 1 & 1 & P.cathemerium \\
\hline Northern flicker & 0 & 0 & 1 & \\
\hline Total & 8 & 6 & 26 & \\
\hline
\end{tabular}

Haemosporida lineages recovered from each host are listed.

${ }^{1}$ Two Plasmodium lineages were recovered from the same host individual.

${ }^{2}$ The lineages of two Haemosporida infections were not identified.

mainly in adult birds. In contrast to the WNV serostatus effect, birds that had an active WNV infection were equally likely to have a Plasmodium infection as birds that did not have a WNV infection. These data suggest that WNV and Plasmodium parasites do co-occur and potentially interact within hosts.

Several non-mutually exclusive mechanisms might account for the negative association between the presence of WNV antibodies and the probability of infection with avian Plasmodium. First, confounding ecological factors may result in patterns consistent with real interactions between pathogens, even though these interactions do not actually occur within hosts [46]. Shared hosts and vectors predict a passive positive association between the pathogens. However, differing temporal patterns of WNV-seropositive and Plasmodium-infected hosts (perhaps related to environmental variables like temperature or vernal recrudescence of previously acquired Plasmodium infections [14]) might produce an apparent negative association between the pathogens. We show that Plasmodium infections do appear earlier within a transmission season than WNV antibodies among adult hosts in Chicago, IL. However, analyses focused on a period when WNV seropositive and Plasmodium infected hosts overlap temporally showed a negative association between the presence of WNV antibodies and Plasmodium. This suggests that asynchronous infection dynamics do not solely drive an inverse relationship between WNV serostatus and Plasmodium infection status.

Second, WNV and Plasmodium may compete directly within a host. Direct competition for host nutrients or cell types could reduce co-occurrence between the pathogens within a host. WNV is known to cause anemia in some birds [47], and thus may reduce the amount red blood cells available to Plasmodium parasites. The availability of red blood cells may influence the invasion success of Plasmodium parasites, parasitemia, or the persistence of parasites within the bloodstream. For instance, anemia-inducing helminths lower the parasitemia of microparasites that require red blood cells in rodents [4]. However, direct competition would be expected to occur in both juvenile and adult hosts similarly. The apparent restriction of the WNV serostatus effect to adult hosts may suggest this mechanism is less likely.

Third, WNV and Plasmodium parasites may interact indirectly, mediated through the host immune system. For instance, a pathogen may "prime" a host's immune system to respond to a secondary pathogen and thus influence 
the potential for co-infection [3]. While direct crossover immunity would not be expected between WNV and Plasmodium given the biological differences between the pathogens, suppression of one infection by the other has been reported for concurrent infections of Plasmodium and other viruses [12]. These effects may be mediated by the Th1 and Th2 polarization of mammalian [48] and avian immune systems [49]. While immune responses to both pathogens are varied, viruses and intracellular microparasites like Plasmodium typically activate a Th1 response associated with cell-mediated immunity. Since both WNV and Plasmodium elicit the same general cytokine response, the immune response toward one pathogen may also counteract infections by the other [3]. However, Haemoproteus may elicit a similar general cytokine response as Plasmodium. The lack of a similar relationship between Haemoproteus infection and WNV serostatus makes this mechanism somewhat dubious.

Alternatively, co-infection with WNV and Plasmodium may reduce host survival, producing an apparent negative association between these pathogens among hosts. Both Plasmodium and WNV can produce broad pathological changes in infected avian hosts and fitness consequences for hosts have been documented for each pathogen independently $[14,19,50,51]$. Co-infections may induce an additive effect on mortality probabilities, either by disrupting important physiological processes, or making death by other extrinsic factors (ie. predation) more likely [52]. Given broad differences in the physiology and causes of mortality between juvenile and adult birds, mechanisms mediated by host physiology could produce different outcomes of pathogen association across age class. Moreover, different patterns of virulence across Haemosporida genera and lineages [11,14] can lead to different physiological consequences of a WNV co-infection for host individuals.

Identifying the mechanisms that drive an inverse association between WNV serostatus and Plasmodium infection status may provide integrated perspectives on host health and demography because alternate mechanisms may impact host survival and disease transmission dynamics differently [3]. For instance, if co-infections elevate the risk of host mortality, Plasmodium may have played a role in declines of North American bird populations following the introduction of WNV [24]. Interactions with Plasmodium could also impact WNV transmission. If a Plasmodium infection primes the immune system against WNV, Plasmodium transmission might lower the average host competence for WNV and reduce the potential for WNV transmission. Alternatively, existing Plasmodium infections could prolong or intensify a WNV infection, increasing the transmission potential or force of infection exerted by the host. Additionally, if co-infection is associated with increased host mortality, WNV transmission could be impacted by a reduction in recovered hosts that act as sinks in the transmission cycle [53]. Ultimately, controlled experimental infection studies are necessary to understand WNVPlasmodium interactions, and test mechanisms that may produce the inverse association between WNV serostatus and Plasmodium infection status among avian hosts. Such studies could shed more light on the implications of potential interactions between these pathogens among wild birds.

\section{Conclusions}

Our results indicate a negative association between West Nile virus serostatus and Plasmodium parasites among adult avian hosts within a suburban hotspot of WNV transmission. The correlational nature of the data makes it difficult to identify the mechanism driving this effect. Nevertheless, these results highlight the potential for direct or indirect interactions between these common avian pathogens. Such interactions may have important consequences on host physiology and fitness that may ultimately impact host populations. Further study involving experimental infections are necessary to clarify the mechanisms driving the negative association between WNV and avian Plasmodium observed here. Identifying these mechanisms represents a fundamental step toward understanding the potential influence that ubiquitous Haemosporida infections may have on the transmission of a zoonotic pathogen such as WNV.

\section{Additional file}

Additional file 1: This supporting file contains a data summary table, a phylogeny of haemosporidian parasite lineages based on the cytochrome b gene, and full AICc summary tables presenting the results of the analyses presented here.

\section{Abbreviations}

AIC: Aikake information crieteria; AICc: "corrected" Aikake information crieteria; CDC: Centers for disease control and prevention;

GLMM: Generalized linear mixed model; WNV: West Nile virus.

\section{Competing interests}

The authors declare that they have no competing interests.

\section{Authors' contributions}

U.D.K, T.L.G., E.D.W., J.D.B., M.O.R., M.C.M., and R.E.R procured resources to support sample collection and sample analysis. G.L.H, T.K.A. and B.L.K contributed strongly to data collection. M.C.M screened and characterized all Haemosporida infections. M.C.M, J.M.H., and G.L.H. conceived the analysis and analyzed the data. All authors helped interpret the results. M.C.M wrote the manuscript with contributions from all authors. All authors read and approved the final version of the manuscript.

\section{Acknowledgements}

We thank the villages of Alsip, Evergreen Park, Oak Lawn, and Palos Hills, and many private homeowners for granting us permission to conduct this study on their properties. Field assistance was provided by Scott Loss, Tim Thompson, Diane Gohde, Mike Goshorn, and Seth Dallmann. Emily Boothe screened WNV positive birds for malaria parasites. The collection of samples 
in Chicago, IL and WNV screening was supported by the National Science Foundation grants EF-0429124 and EF-0840403 to UDK, JDB, TLG, MOR, and EDW. Malaria screening was supported by the National Science Foundation grant DEB-054239, the Whitney Harris World Ecology Center, the St. Louis Audubon Society, the Curators of the University of Missouri, and the University of Missouri-St. Louis Dissertation Fellowship awarded to MCM.

\section{Author details}

'Department of Biology, University of Missouri-St. Louis, One University Boulevard, St. Louis, MO 63121, USA. ²Department of Biology, Georgia Southern University, P.O. Box 8042-1, Statesboro 30460, Georgia. ${ }^{3}$ Department of Environmental Studies, Emory University, 400 Dowman Drive, Atlanta, GA 30322, USA. ${ }^{4}$ Department of Microbiology and Molecular Genetics, 2215 Biomedical Physical Sciences East, Lansing, Ml 48824-4320, USA. ${ }^{5}$ Department of Natural Resources and Environmental Sciences, University of Illinois, 1102 South Goodwin Ave., Urbana, IL 61801, USA. ${ }^{6}$ Department of Pathobiology, University of Illinois, 2001 S. Lincoln, Urbana, IL 61801, USA. 'Department of Pathobiological Sciences, University of Wisconsin, 2015 Linden Dr., Madison, WI 53706, USA. ${ }^{8}$ Department of Entomology, Texas A\&M University, 2475 TAMU, College Station, TX 77843-2475, USA.

Received: 24 June 2014 Accepted: 20 August 2014

Published: 1 September 2014

\section{References}

1. Ezenwa VO, Etienne RS, Luikart G, Beja-Pereira A, Jolles AE: Hidden consequences of living in a wormy world: nematode induced immune suppression facilitates tuberculosis invasion in African buffalo. Am Nat 2010, 176:613-624.

2. Telfer $S$, Lambin $X$, Birtles R, Beldomenico P, Burthe S, Paterson S, Begon M: Species interactions in a parasite community drive infection risk in a wildlife population. Science 2010, 330:243-246.

3. Graham AL, Cattadori IM, Lloyd-Smith JO, Ferrari MJ, Bjørnstad ON: Transmission consequences of coinfection: cytokines writ large? Trends Parasitol 2007, 23:284-291.

4. Graham AL: Ecological rules governing helminth-microparasite coinfection. Proc Natl Acad Sci U S A 2008, 105:566-570.

5. Atkinson CT, Lease JK, Dusek RJ, Samuel MD: Prevalence of pox-like lesions and malaria in forest bird communities on leeward Mauna Loa Volcano, Hawaii. Condor 2005, 107:537-546.

6. Graham AL, Lamb TJ, Read AF, Allen JE: Malaria-filaria coinfection in mice makes malarial disease more severe unless filarial infection achieves patency. J Infect Dis 2005, 191:410-421.

7. Knowles SCL: The effect of helminth co-infection on malaria in mice: a meta-analysis. Int J Parasitol 2011, 41:1041-1051.

8. Johnson PTJ, Hoverman JT: Parasite diversity and coinfection determine pathogen infection success and host fitness. Proc Natl Acad Sci U S A 2012, 109:9006-9011.

9. van Rooyen J, Lalubin F, Glaizot O, Christe P: Avian haemosporidian persistence and co-infection in great tits at the individual level. Malar $\mathrm{J}$ 2013, 12:40

10. Marzal A, Bensch S, Reviriego M, Balbontin J, De Lope F: Effects of malaria double infection in birds: one plus one is not two. J Evolution Biol 2008, 21:979-987.

11. Palinauskas V, Valkiūnas $G$, Bolshakov CV, Bensch S: Plasmodium relictum (lineage SGS1) and Plasmodium ashfordi (lineage GRW2): the effects of the co-infection on experimentally infected passerine birds. Exp Parasitol 2011, 127:527-533.

12. Cox FE: Concomitant infections, parasites and immune responses. Parasitology 2001, 122(Suppl):S23-S38.

13. Barnett HC: Experimental studies of concurrent infection of canaries and of the mosquito Culex tarsalis with Plasmodium relictum and western equine encephalitis virus. Am J Trop Med Hyg 1956, 5:99-109.

14. Valkiūnas G: Avian Malaria Parasites and Other Haemosporidia. Boca Raton: CRC Press; 2005.

15. Atkinson CT, Van Riper C III: Pathogenecity and Epizootiology of Avian Haematozoa: Plasmodium, Leucocytozoon, and Haemoproteus. In BirdParasite Interactions. Ecology, Evolution, and Behavior. Edited by Loye JE, Zuk M. New York: Oxford University Press; 1991:19-48.
16. Knowles SCL, Palinauskas V, Sheldon BC: Chronic malaria infections increase family inequalities and reduce parental fitness: experimental evidence from a wild bird population. J Evolution Biol 2010, 23:557-569.

17. Martínez-de la Puente J, Merino S, Tomás G, Moreno J, Morales J, Lobato E, García-Fraile S, Belda EJ: The blood parasite Haemoproteus reduces survival in a wild bird: a medication experiment. Biol Lett 2010, 6:663-665.

18. Lachish S, Knowles SCL, Alves R, Wood MJ, Sheldon BC: Fitness effects of endemic malaria infections in a wild bird population: the importance of ecological structure. J Anim Ecol 2011, 80:1196-1206.

19. Palinauskas V, Valkiūnas $\mathrm{G}$, Bolshakov CV, Bensch S: Plasmodium relictum (lineage P-SGS1): effects on experimentally infected passerine birds. Exp Parasitol 2008, 120:372-380.

20. Petersen LR, Hayes EB: West Nile virus in the Americas. Med Clin N Am 2008, 92:1307-1322. ix.

21. Kilpatrick AM, LaDeau SL, Marra PP: Ecology of West Nile virus transmission and its impact on birds in the western hemisphere. Auk 2007, 124:1121-1136.

22. Hayes EB, Sejvar JJ, Zaki SR, Lanciotti RS, Bode AV, Campbell GL: Virology, pathology, and clinical manifestations of West Nile virus disease. Emerg Infect Dis 2005, 11:1174-1179.

23. Yaremych SA, Warner RE, Mankin PC, Brawn JD, Raim A, Novak R: West Nile virus and high death rate in American crows. Emerg Infect Dis 2004, 10:709-771.

24. LaDeau SL, Kilpatrick AM, Marra PP: West Nile virus emergence and large-scale declines of North American bird populations. Nature 2007, 447:710-713.

25. van Dyken M, Bolling BG, Moore CG, Blair CD, Beaty BJ, Black WC IV, Foy BD: Molecular evidence for trypanosomatids in Culex mosquitoes collected during a West Nile virus survey. Int J Parasitol 2006, 36:1015-1023.

26. Newman CM, Cerutti F, Anderson TK, Hamer GL, Walker ED, Kitron UD, Ruiz MO, Brawn JD, Goldberg TL: Culex Flavivirus and West Nile virus mosquito coinfection and positive ecological association in Chicago, United States. Vector Borne Zoonotic Dis 2011, 11:1099-1105.

27. Medeiros MC, Hamer GH, Ricklefs RE: Host compatibility rather than vector-host encounter rate determines the host range of avian Plasmodium parasites. Proc R Soc B 2013, 280:20122947.

28. Komar N, Langevin S, Hinten S, Nemeth N, Edwards E, Hettler D, Davis B, Bowen R, Bunning M: Experimental infection of North American birds with the New York 1999 strain of West Nile virus. Emerg Infect Dis 2003, 9:311-322.

29. Komar N, Panella NA, Langevin SA, Brault AC, Amador M, Edwards E, Owen JC: Avian hosts for West Nile virus in St. Tammany Parish, Louisiana, 2002. Am J Trop Med Hyg 2005, 73:1031-1037.

30. Kilpatrick AM, Daszak P, Jones MJ, Marra PP, Kramer LD: Host heterogeneity dominates West Nile virus transmission. Proc R Soc B 2006, 273:2327-2333.

31. Hamer GL, Chaves LF, Anderson TK, Kitron UD, Brawn JD, Ruiz MO, Loss SR, Walker ED, Goldberg TL: Fine-scale variation in vector host use and force of infection drive localized patterns of West Nile virus transmission. PLOS ONE 2011, 6:e23767.

32. Hamer GL, Kitron UD, Brawn JD, Loss SR, Ruiz MO, Goldberg TL, Walker ED Culex pipiens (Diptera: Culicidae): a bridge vector of West Nile virus to humans. J Med Entomol 2008, 45:125-128.

33. Kilpatrick AM, Kramer LD, Campbell SR, Alleyne EO, Dobson AP, Daszak P: West Nile virus risk assessment and the bridge vector paradigm. Emerg Infect Dis 2005, 11:425-429.

34. Kimura M, Darbro JM, Harrington LC: Avian malaria parasites share congeneric mosquito vectors. J Parasitol 2010, 96:144-151.

35. Loss SR, Hamer GL, Walker ED, Ruiz MO, Goldberg TL, Kitron UD, Brawn JD: Avian host community structure and prevalence of West Nile virus in Chicago, Illinois. Oecologia 2009, 159:415-424.

36. Fallon SM, Ricklefs RE, Swanson BL, Bermingham E: Detecting avian malaria: an improved polymerase chain reaction diagnostic. J Parasitol 2003, 89:1044-1047.

37. Ricklefs RE, Swanson BL, Fallon SM, Martinez-Abrain A, Scheuerlein A, Gray J, Latta SC: Community relationships of avian malaria parasites in southern Missouri. Ecol Monogr 2005, 75:543-559.

38. Fecchio A, Lima MR, Svensson-Coelho M, Marini MÂ, Ricklefs RE: Structure and organization of an avian haemosporidian assemblage in a Neotropical savanna in Brazil. Parasitology 2013, 140:181-192.

39. Bensch S, Pérez-Tris J, Waldenström J, Hellgren O: Linkage between nuclear and mitochondrial DNA sequences in avian malaria parasites: multiple cases of cryptic speciation? Evolution 2004, 58:1617-1621. 
40. Martinsen ES, Paperna I, Schall JJ: Morphological versus molecular identification of avian Haemosporidia: an exploration of three species concepts. Parasitology 2006, 133:279-288.

41. Martinsen ES, Waite JL, Schall JJ: Morphologically defined subgenera of Plasmodium from avian hosts: test of monophyly by phylogenetic analysis of two mitochondrial genes. Parasitology 2007, 134:483-490

42. Hamer GL, Walker ED, Brawn JD, Loss SR, Ruiz MO, Goldberg TL, Schotthoefer AM, Brown WM, Wheeler E, Kitron UD: Rapid amplification of West Nile virus: the role of hatch-year birds. Vector Borne Zoonotic Dis 2008, 8:57-67.

43. Hamer GL, Anderson TK, Berry GE, Makohon-Moore AP, Crafton JC, Brawn JD, Dolinski AC, Krebs BL, Ruiz MO, Muzzall PM, Goldberg TL, Walker ED: Prevalence of filarioid nematodes and trypanosomes in American robins and house sparrows, Chicago USA. Int J Parasitol Parasites Wildl 2013, 2:42-49.

44. Tamura K, Peterson D, Peterson N, Stecher G, Nei M, Kumar S: MEGA5: molecular evolutionary genetics analysis using maximum likelihood, evolutionary distance, and maximum parsimony methods. Mol Biol Evol 2011, 28:2731-2739.

45. Burnham K, Anderson D: Model Selection and Multimodel Inference: a Practical Information-Theoretic Approach. New York: Springer; 2002.

46. Hellard E, Pontier D, Sauvage F, Poulet H, Fouchet D: True versus false parasite interactions: a robust method to take risk factors into account and its application to feline viruses. PLoS ONE 2012, 7:e29618.

47. Joyner PH, Kelly S, Shreve AA, Snead SE, Sleeman JM, Pettit DA: West Nile virus in raptors from Virginia during 2003: clinical, diagnostic, and epidemiologic findings. J Wildl Dis 2006, 42:335-344.

48. Mosmann TR, Cherwinski H, Bond MW, Giedlin MA, Coffman RL: Two types of murine helper T cell clone. I. Definition according to profiles of lymphokine activities and secreted proteins. J Immunol 1986, 136:2348-2357.

49. Schwarz A, Gauly M, Abel H, Daş G, Humburg J, Rohn K, Breves G, Rautenschlein S: Immunopathogenesis of Ascaridia galli infection in layer chicken. Dev Comp Immunol 2011, 35:774-784.

50. Cellier-Holzem E, Esparza-Salas R, Garnier S, Sorci G: Effect of repeated exposure to Plasmodium relictum (lineage SGS1) on infection dynamics in domestic canaries. Int J Parasitol 2010, 40:1447-1453.

51. Steele KE, Linn MJ, Schoepp RJ, Komar N, Geisbert TW, Manduca RM, Calle PP, Raphael BL, Clippinger TL, Larsen T, Smith J, Lanciotti RS, Panella NA, McNamara TS: Pathology of fatal West Nile virus infections in native and exotic birds during the 1999 Outbreak in New York City, New York. Vet Pathol Online 2000, 37:208-224.

52. Møller AP, Nielsen JT: Malaria and risk of predation: a comparative study among birds. Ecology 2007, 88:871-881.

53. Foppa IV, Spielman A: Does reservoir host mortality enhance transmission of West Nile virus? Theor Biol Med Model 2007, 4:17.

doi:10.1186/1756-3305-7-415

Cite this article as: Medeiros et al:: An inverse association between West Nile virus serostatus and avian malaria infection status. Parasites \& Vectors 2014 7:415.

\section{Submit your next manuscript to BioMed Central and take full advantage of:}

- Convenient online submission

- Thorough peer review

- No space constraints or color figure charges

- Immediate publication on acceptance

- Inclusion in PubMed, CAS, Scopus and Google Scholar

- Research which is freely available for redistribution

Submit your manuscript at www.biomedcentral.com/submit
C Biomed Central 